\title{
Energia dietética ao final da gestação e durante a lactação e desempenho de ovinos Santa Inês em sistema de acasalamento acelerado
}

\section{Dietary energy in late pregnancy and during lactation and performance of Santa Inês sheep in an accelerated mating system}

\author{
Filipe Alexandre Boscaro de Castro $^{1^{*}}$; Edson Luis de Azambuja Ribeiro ${ }^{2}$; \\ Ivone Yurika Mizubuti ${ }^{2}$; Leandro das Dores Ferreira da Silva ${ }^{3}$; \\ Marco Aurélio Alves de Freitas Barbosa ${ }^{3}$; Bruno Marson ${ }^{4}$; \\ Fernando Augusto Grandis'; ${ }^{4}$ Francisco Fernandes Junior ${ }^{4}$; Elzânia Sales Pereira ${ }^{5}$
}

\section{Resumo}

\begin{abstract}
Objetivou-se avaliar teores de energia na alimentação de ovelhas no terço final de gestação e lactação, em sistema de acasalamento acelerado. Foram avaliadas três rações com diferentes teores de energia: 2,0; 2,2 e 2,4 Mcal de EM/kg de MS, distribuídas aleatoriamente às ovelhas. Os animais foram alimentados com as rações experimentais durante o terço final da gestação e na lactação, em três ciclos produtivos consecutivos. Antes do início de cada período de fornecimento das rações experimentais, foram selecionadas apenas fêmeas com gestação de um cordeiro, a partir de um rebanho de 50 animais, sendo que foram utilizadas 18; 19 e 18 ovelhas no primeiro, segundo e terceiro ciclo, respectivamente. Ao início de cada período experimental as ovelhas encontravam-se aos 105 dias de gestação, com peso corporal médio de $52,00 \mathrm{~kg}$ e escore corporal médio de 3,00. Os cordeiros nascidos permaneceram com suas mães até o desmame, realizado aos 60 dias. Após o desmame todas as ovelhas foram manejadas em pastagem, suplementadas diariamente com silagem de sorgo e ração concentrada a base de milho e farelo de soja. Objetivou-se através do manejo reprodutivo a redução no intervalo de parto. Do início do fornecimento das rações ao desmame houve aumento linear nos pesos e escores corporais das ovelhas à medida que os teores energéticos aumentaram. Verificou-se efeito linear positivo dos teores de energia nos peso dos cordeiros, do nascimento ao desmame, e no ganho médio diário de peso $(0,125 ; 0,176$ e $0,220 \mathrm{~kg} /$ dia para 2,0;2,2 e 2,4 , respectivamente). Fêmeas alimentadas com 2,0 Mcal de EM/kg de MS apresentaram os piores índices para taxa de parição $(66,7 ; 100,0$ e $83,3 \%)$, taxa de nascimentos $(72,2 ; 105,3$ e 88,9\%) e período de serviço $(131,1 ; 128,4$ e 122,2 dias, para 2,0; 2,2 e 2,4, respectivamente). A época de fornecimento das rações não influenciou nenhum dos parâmetros produtivos ou reprodutivos avaliados. Ovelhas Santa Inês podem ser utilizadas para produção de cordeiros em sistema de acasalamento acelerado, desde que seja controlado o manejo nutricional do rebanho visando a manutenção de escores corporais intermediários (2,5 a 3,5). Dieta contendo 2,0 Mcal EM/kg de MS não atende as exigências energéticas de ovelhas Santa Inês em final de gestação e durante a lactação.
\end{abstract}

Palavras-chave: Condição corporal, cordeiro, ganho de peso, nutrição, ovelha, reprodução

\footnotetext{
${ }^{1}$ Discente de Doutorado do Programa de Pós-Graduação em Ciência Animal, Universidade Estadual de Londrina, UEL, Londrina, PR. E-mail: fabcastro76@yahoo.com.br

${ }^{2}$ Profs. Drs. do Dept ${ }^{\circ}$ de Zootecnia, UEL, Londrina, PR. Bolsista de Produtividade do CNPq. E-mail: elar@uel.br; mizubuti@uel.br

${ }^{3}$ Profs. Drs. do Dept ${ }^{\circ}$ de Zootecnia, UEL, Londrina, PR. E-mail: leandro@uel.br; maafbarbosa@uel.br

${ }^{4}$ Discentes de Mestrado do Programa de Pós-Graduação em Ciência Animal, UEL, Londrina, PR. E-mail: bruno-marson@hotmail. com; fernando_grandis@yahoo.com.br; ffjunior_zoo@hotmail.com

${ }^{5}$ Prof $^{a}$ Dr $^{\mathrm{a}}$ do Dept ${ }^{\mathrm{o}}$ de Zootecnia, Universidade Federal do Ceará, UFC, Ceará, CE. Bolsista de Produtividade do CNPq. E-mail: elzania@hotmail.com

* Autor para correspondência
} 


\begin{abstract}
The objective of this study was to evaluate feed energy concentration in the last third of gestation and during lactation of ewe in an accelerated mating system. Three rations with different energy content were evaluated: $2.0 ; 2.2$ and $2.4 \mathrm{Mcal}$ of $\mathrm{ME} / \mathrm{kg} \mathrm{DM}$, which were randomly distributed to the animals. Experimental rations were fed to animals in the last third of gestation and lactation for three consecutive productive cycles. Before start each period of provision of the rations, only females gestating one lamb were selected from a flock of 50 animals, being utilized 18; 19 and 18 ewes in the first, second and third cycle, respectively. At the beginning of each experimental period, ewes were at 105 days of gestation with an average body weight of $52.00 \mathrm{~kg}$ and average body condition score of 3.00. Newborn lambs remained with their mothers until weaning, at 60 days of age. After weaning, all ewes were managed on pasture, being supplemented daily with sorghum silage and concentrate based on corn and soybean meal. It was aimed the reduction of lambing interval through the reproductive management. From the beginning of the provision of the rations until weaning there was a linear increase in body weight and body condition of the ewes, as energy concentration increased. It was also verified a positive linear effect of energy content on weight of lambs from birth to weaning, and on average daily weight gain $(0.125 ; 0.176$ and $0.220 \mathrm{~kg} /$ day, for $2.0 ; 2.2$ and 2.4, respectively). Females fed with $2.0 \mathrm{Mcal}$ of ME/ $\mathrm{kg}$ of DM presented the worst indices for lambing rate $(66.7 ; 100.0$ and $83.3 \%)$, birth rate $(72.2 ; 105.3$ and $88.9 \%$ ) and service period $(131.1 ; 128.4$ and 122.2 days, for 2.0, 2.2 and 2.4, respectively). The season of provision of rations did not affect any of the productive or reproductive parameters evaluated. Santa Inês ewes can be used for lamb production in an accelerated mating system, since the nutritional management of the herd is controlled in order to maintain intermediate body scores (2.5 to 3.5). Diet containing 2.0 Mcal ME/kg DM do not meet energy requeriments for Santa Inês ewes in late pregnancy and during lactation.
\end{abstract}

Key words: Body condition, ewe, lamb, nutrition, reproduction, weight gain

\section{Introdução}

O crescimento contínuo do rebanho ovino brasileiro, registrado pelo IBGE (2013) nos últimos anos, tem estimulado o surgimento de pesquisas que objetivam preencher lacunas existentes com relação à adoção de práticas de alimentação adequadas às várias fases do sistema produtivo.

Na maioria dos sistemas de criação de ovinos, a energia é considerada o primeiro nutriente limitante e as dietas são inicialmente formuladas para satisfazer as exigências energéticas (SINCLAIR; WILKINSON, 1999). Segundo o NRC (1985), a deficiência energética é a deficiência nutricional de maior ocorrência na ovinocultura. Por outro lado, o excesso no fornecimento de energia para ovinos é a prática de maior desperdício. Ambas as situações significam perdas econômicas ao produtor.

Durante toda a gestação em ruminantes, o desenvolvimento e a sobrevivência do concepto estão subordinados ao fornecimento uterino de nutrientes oriundos da alimentação materna (MARTIN; RODGER; BLACHE, 2004). Os primeiros cem dias de gestação são marcados pela diferenciação dos órgãos e tecidos do feto, sendo que nesta fase as matrizes poderão receber uma alimentação que satisfaça as suas exigências nutricionais de mantença (PILAR; PÉREZ; SANTOS, 2002). Já na fase final da gestação observa-se que as exigências em energia das ovelhas aumentam, em relação à mantença, em torno de $54 \%$ para gestações simples e 95\% para gestações gemelares (NRC, 2007). A elevação da exigência energética acontece porque, neste período, o feto cresce cerca de $70 \%$ do seu peso corporal (PILAR; PÉREZ; SANTOS, 2002), assim como ocorre o desenvolvimento do tecido mamário em preparação para a lactação (MELLOR, 1987; SAINZ, 2010).

A glicose, um dos principais nutrientes oriundos da alimentação materna, é utilizada pelos tecidos fetais e placentários como principal substrato energético para o seu metabolismo (BROLIO et 
al., 2010). O aumento na concentração de glicose plasmática da ovelha está essencialmente associado à elevação de ácido propiônico produzido no rúmen (FRANDSON; WILKE; FAILS, 2005), substrato para gliconeogênese hepática, sendo o principal precursor da glicose em ruminantes (VALADARES FILHO; PINA, 2011). Charismiadou, Bizelis e Rogdakis (2000) afirmaram que a taxa de produção de propionato ruminal é significativamente afetada pelo nível nutricional. Deste modo, uma restrição alimentar imposta à mãe durante a gestação pode reduzir o transporte de nutrientes no ambiente placentário, comprometendo o suprimento energético do embrião e do feto, levando as ovelhas a parir com menores pesos corporais e também fetos mais leves.

A subnutrição materna no final da gestação também causa redução no desenvolvimento mamário, com consequente limitação na capacidade de produção de colostro e leite pela ovelha (MELLOR, 1987), impactando sobre o crescimento e sobrevivência dos cordeiros.

Charismiadou, Bizelis e Rogdakis (2000) destacaram que em determinadas circunstâncias a alimentação inadequada no final da gestação pode também afetar a saúde da ovelha determinando, por exemplo, a ocorrência de toxemia da prenhez que pode levar o animal a morte.

O correto manejo nutricional das ovelhas no final da gestação e, sobretudo na lactação, capacita as fêmeas a atingirem ritmos reprodutivos mais acelerados (SAINZ, 2010). Na relação existente entre nutrição e reprodução, a energia é o nutriente mais importante (CEZAR; SOUSA, 2006), pois promove elevação nos níveis de insulina circulantes (CUNNINGHAM; KLEIN, 2008) que estimulam o hipotálamo a aumentar a frequência dos pulsos de GnRH, favorecendo a atividade gonadal (MARTIN; RODGER; BLACHE, 2004).

Tendo em vista o exposto, objetivou-se com este trabalho avaliar teores de energia na alimentação de ovelhas durante o terço final de gestação e lactação, em sistema de acasalamento acelerado.

\section{Material e Métodos}

O experimento foi conduzido no setor de ovinocultura da Fazenda Escola da Universidade Estadual de Londrina. Esta propriedade localizase no município de Londrina (Lat. S. 2320'10" e Long. W. 5109'15”), com 610 metros de altitude, temperatura ambiente média anual variando de $21,0^{\circ} \mathrm{C}$ a $22,0^{\circ} \mathrm{C}$, sendo a média dos meses mais quentes (Janeiro e Fevereiro) de $24,5^{\circ} \mathrm{C}$ e a média do mês mais frio (Junho) de $16,5^{\circ} \mathrm{C}$. A precipitação média anual varia de 1400 a $1600 \mathrm{~mm}$, sendo Dezembro, Janeiro e Fevereiro os meses mais chuvosos e Junho, Julho e Agosto os meses mais secos (CAVIGLIONE et al., 2000).

Foram avaliadas três rações isoprotéicas e com diferentes teores de energia metabolizável (EM): 2,0; 2,2 e 2,4 Mcal de EM/kg de MS (Tabela 1), as quais foram distribuídas aleatoriamente às ovelhas devidamente confinadas em aprisco com piso ripado e baias individuais com dimensão aproximada de $1,3 \times 2 \mathrm{~m}$. As ovelhas foram alimentadas com as rações experimentais durante o terço final da gestação e toda a lactação, em três ciclos produtivos consecutivos. Antes do início de cada período de fornecimento das rações experimentais, foram selecionadas apenas fêmeas adultas com gestação de um cordeiro, confirmada por meio da técnica de ultrassonografia, a partir de um rebanho de 50 animais. As ovelhas selecionadas foram sorteadas entre as rações experimentais, sendo que foram utilizadas 18; 19 e 18 fêmeas no primeiro, segundo e terceiro ciclo, respectivamente. Ao início de cada período experimental as ovelhas encontravam-se aos 105 7,39 dias de gestação, com peso corporal médio de $52,38 \pm 7,38 \mathrm{~kg}$ e escore de condição corporal médio de $3,00 \pm 0,58$. Para determinação do escore de condição corporal foi realizada palpação da coluna vertebral após a última costela, acima da região dos rins, de acordo com metodologia descrita por Osório e Osório (2005). Atribuiu- 
se valores de 1 a 5 , sendo que 1 corresponde a animais excessivamente magros e 5 a animais excessivamente gordos, considerando-se também valores intermediários em variações de 0,25.

Tabela 1. Composição química das rações experimentais (\%MS).

\begin{tabular}{lccc}
\hline \multirow{2}{*}{ Componentes nutritivos } & \multicolumn{3}{c}{ Teor de energia metabolizável (Mcal/kg de MS) } \\
\cline { 2 - 4 } & 2,0 & 2,2 & 2,4 \\
\hline Matéria seca & 27,20 & 30,17 & 34,85 \\
Matéria orgânica & 92,30 & 92,85 & 93,37 \\
Proté́na bruta & 10,63 & 10,35 & 10,38 \\
Extrato etéreo & 1,37 & 1,73 & 2,12 \\
Matéria mineral & 7,70 & 7,15 & 6,63 \\
Fibra em detergente neutro & 71,87 & 62,37 & 49,87 \\
Fibra em detergente ácido & 39,53 & 34,10 & 26,87 \\
Nutrientes digestíveis totais $^{1}$ & 55,80 & 60,47 & 66,30 \\
\hline
\end{tabular}

${ }^{1}$ Estimado a partir da composição dos alimentos segundo equações propostas por McDowell et al. (1974).

Fonte: Elaboração dos autores.

As rações foram fornecidas à vontade duas vezes ao dia, às $7 \mathrm{~h} 30$ e às $16 \mathrm{~h} 30$, e permitiramse sobras de $20 \%$ do total oferecido. Foi oferecido água à vontade em bebedouros apropriados.

As rações experimentais foram formuladas após análise química dos alimentos e consistiram de silagem de sorgo e ração concentrada, composta por milho moído, farelo de soja, uréia, fosfato bicálcico, calcário calcítico e sal mineralizado em diferentes proporções, de acordo com o teor de energia (Tabela 2). A energia metabolizável das rações foi calculada de acordo com Sniffen et al. (1992).

Tabela 2. Composição de ingredientes das rações experimentais (\%MS).

\begin{tabular}{lccc}
\hline \multirow{2}{*}{ Ingredientes } & Teor de energia metabolizável (Mcal/kg de MS) & 2,4 \\
\cline { 2 - 4 } & 2,0 & 2,2 & 63,2 \\
Silagem de sorgo & 96,5 & 82,2 & 32,6 \\
Milho moído & 0,0 & 13,1 & 1,9 \\
Farelo de soja & 1,3 & 2,7 & 0,5 \\
Uréia & 0,7 & 0,5 & 0,3 \\
Fosfato bicálcico & 0,4 & 0,3 & 0,5 \\
Calcário calcítico $_{\text {Mistura mineral }^{1}}$ & 0,1 & 0,2 & 1,0 \\
\hline
\end{tabular}

${ }^{1}$ Níveis de garantia do fabricante para cada 1000g: cálcio (mínimo), 128g; cálcio (máximo), $155 \mathrm{~g}$; sódio, $152 \mathrm{mg}$; fósforo, $60 \mathrm{~g}$; enxofre, 10g; magnésio, 6g; cobalto, 50mg; ferro, $1400 \mathrm{mg}$; iodo, $74 \mathrm{mg}$; manganês, $1820 \mathrm{mg}$; selênio, $15 \mathrm{mg}$; zinco, 2730mg; flúor (máximo), 600mg.

Fonte: Elaboração dos autores.

Todas as análises químicas foram realizadas no Estadual de Londrina. Os teores de matéria seca Laboratório de Nutrição Animal da Universidade (MS), matéria mineral (MM), matéria orgânica 
(MO), proteína bruta (PB), extrato etéreo (EE), fibra em detergente neutro (FDN) e fibra em detergente ácido (FDA) foram quantificados de acordo com metodologias descritas por Mizubuti et al. (2009).

Os cordeiros nascidos permaneceram junto de suas mães até o desmame, realizado aos 60 dias de idade. Após o desmame, as ovelhas de todos os tratamentos foram manejadas em pastagem de Panicum maximum cv. Aruana e Cynodon dactylon cv. Coast cross (6 piquetes de 0,5 hectares cada) sendo suplementadas às $16 \mathrm{~h} 00$ com silagem de sorgo e ração concentrada (relação volumoso: concentrado $=70: 30$ ) composta por farelo de milho (80\%) e farelo de soja (20\%). A suplementação com aproximadamente $2 \mathrm{~kg}$ por animal foi realizada em cochos de concreto em curral semicoberto de piso também concretado.

Durante o período pré-experimental realizouse, em maio de 2009, o acasalamento das ovelhas com utilização de machos da raça Santa Inês. A identificação das ovelhas acasaladas foi feita pela técnica de tinta na região esterno-ventral do corpo do carneiro com inspeção diária do rebanho.

Objetivou-se por meio do manejo reprodutivo a redução do intervalo de parto. Para isso, foram realizadas estações reprodutivas de 45 dias em fev/mar de 2010, nov/dez de 2010 e ago/set de 2011. Estas estações de monta corresponderam, respectivamente, às reproduções subsequentes ao fornecimento das rações experimentais em set-dez de 2009 (época I), jun-set de 2010 (época II) e marjun de 2011 (época III).

Amostras das rações experimentais foram coletadas semanalmente a fim de se obter a composição química. Por não terem sido constatadas variações significativas na composição química das rações utilizadas nos diferentes períodos produtivos avaliados, foram apresentadas as médias dos componentes nutritivos para as três épocas de observação (Tabela 1).

A profilaxia parasitária foi realizada antes de cada período de confinamento com a aplicação de anti-helmíntico em ovelhas que apresentaram resultados laboratoriais acima de 500 ovos por grama de fezes (OPG). Para o diagnóstico de OPG foi utilizado o método de Gordon e Whitlock, descrito por Hoffmann (1987). Durante os períodos compreendidos entre a desmama e o confinamento seguinte, os quais as ovelhas foram manejadas a pasto, o diagnóstico de OPG foi realizado mensalmente, sendo também tratados aqueles animais com contagem superior a 500 .

Os pesos das ovelhas e dos cordeiros e escores de condição corporal das ovelhas foram mensurados semanalmente, sempre no mesmo horário, antes do fornecimento da ração no período da manhã.

Foi avaliado o desempenho reprodutivo das ovelhas após o recebimento das dietas experimentais. Para isso foram medidas as taxas de prenhez ((número de ovelhas prenhes/número de ovelhas acasaladas) x 100) ao final das estações de monta com auxílio da técnica de ultrassonografia, as taxas de parição ((número de ovelhas paridas/número de ovelhas acasaladas) x 100), taxas de nascimentos ((número de cordeiros nascidos/número de ovelhas acasaladas) x 100) e períodos de serviço (período entre o parto e a concepção seguinte).

Para o diagnóstico de gestação por ultrassonografia foi utilizado o aparelho Aloka SSD 500, equipado com um transdutor linear de $5 \mathrm{Mhz}$.

Mediu-se a produção de $\mathrm{kg}$ de cordeiros desmamados por $\mathrm{kg}$ de ovelhas com o intuito de se avaliar a eficiência produtiva dos animais. Para tanto, considerou-se os pesos das ovelhas no início do experimento.

Os dados de peso, escore de condição corporal e período de serviço foram submetidos à análise de variância utilizando-se o procedimento GLM do programa estatístico SAS (Statistical Analysis System, versão 8.2). No modelo estatístico foram consideradas as variáveis independentes: teor energético da ração $(2,4 ; 2,2$ e 2,0 Mcal de EM/kg 
de MS), sexo da cria e época de realização. Para as características que foram influenciadas $(\mathrm{P}<0,05)$ pelos teores de energia na ração os dados foram também submetidos à análise de regressão. Os dados não paramétricos (taxa de prenhez, taxa de parição e taxa de nascimentos) foram analisados utilizando-se o teste de qui-quadrado ou o teste de Fisher com auxílio do mesmo programa estatístico.

\section{Resultados e Discussão}

Médias de peso e de escore de condição corporal (Tabela 3) iniciais das ovelhas não diferiram $(\mathrm{P}>0,05)$ entre os teores energéticos avaliados. Observou- se diferença $(\mathrm{P}<0,05)$ nessas variáveis a partir do parto para os diferentes teores de energia. De acordo com a análise de regressão houve aumento linear nos pesos e escores corporais (Tabela 3 ) à medida que os tores energéticos aumentaram, sendo que os animais alimentados com ração contendo 2,4 Mcal $\mathrm{EM} / \mathrm{kg}$ MS apresentaram médias superiores. O teor energético de 2,0 Mcal EM/kg MS proporcionou médias inferiores de peso e condição corporal. Semelhantemente, Castro et al. (2012) verificaram que a restrição energética de ovelhas no período final de gestação influenciou negativamente as médias de peso e escore de condição corporal dos animais.

Tabela 3. Médias de peso (kg) e escores de condição corporal (escala de 1 a 5) das ovelhas antes e após o parto para os diferentes teores energéticos.

\begin{tabular}{|c|c|c|c|c|c|c|}
\hline \multirow[b]{2}{*}{ Variável } & \multicolumn{3}{|c|}{ Teor de energia metabolizável (Mcal / kg de MS) } & \multirow[b]{2}{*}{ Regressão } & \multirow[b]{2}{*}{$\mathrm{R}^{2}$} & \multirow[b]{2}{*}{$\mathrm{CV}(\%)$} \\
\hline & $2,0(n=18)$ & $2,2(n=19)$ & $2,4(n=18)$ & & & \\
\hline \multicolumn{7}{|c|}{ Pesos } \\
\hline Inicial & 52,91 & 53,15 & 52,02 & $\hat{y}=52,69$ & - & 14,42 \\
\hline Parto $^{1}$ & 49,73 & 55,76 & 59,00 & $\hat{y}=22,55 x+7,89$ & 0,97 & 13,62 \\
\hline Dia $7^{1}$ & 50,07 & 55,91 & 58,37 & $\hat{y}=20,19 x+10,68$ & 0,94 & 13,80 \\
\hline Dia $28^{1}$ & 48,50 & 54,32 & 58,46 & $\hat{y}=24,34 x+0,34$ & 0,99 & 14,17 \\
\hline Desmame $(60 \text { dias })^{1}$ & 46,29 & 53,05 & 58,74 & $\hat{y}=32,59 x-19,16$ & 0,99 & 14,92 \\
\hline \multicolumn{7}{|c|}{ Escore de Condição Corporal } \\
\hline Inicial & 3,08 & 3,06 & 2,92 & $\hat{y}=3,02$ & - & 19,76 \\
\hline Parto $^{1}$ & 2,42 & 3,13 & 3,37 & $\hat{y}=2,79 x-3,15$ & 0,92 & 17,49 \\
\hline Dia $7^{1}$ & 2,21 & 2,89 & 3,17 & $\hat{y}=2,90 x-3,62$ & 0,94 & 17,47 \\
\hline Dia $28^{1}$ & 1,93 & 2,53 & 3,11 & $\hat{y}=3,34 x-4,82$ & 0,99 & 20,05 \\
\hline Desmame $(60 \text { dias })^{1}$ & 1,53 & 2,44 & 3,24 & $\hat{y}=4,69 x-7,91$ & 0,99 & 21,70 \\
\hline
\end{tabular}

$\mathrm{n}=$ número de animais; $\mathrm{R}^{2}=$ coeficiente de determinação; $\mathrm{CV}=$ coeficiente de variação

${ }^{1}$ Regressão linear significativa $(\mathrm{P}<0,05)$

Fonte: Elaboração dos autores.

A energia dietética de 2,0 Mcal EM/kg MS levou as ovelhas a parir com média de escore corporal de 2,42, abaixo do intervalo de 3,0 a 3,5, considerado ideal por Susin (1996) para este momento da vida produtiva da matriz. Ovelhas recebendo rações com 2,2 e 2,4 Mcal EM/kg MS apresentaram médias de escores de condição corporal ao parto de 3,13 e 3,37 , respectivamente, portanto, ambos os valores considerados adequados pela mesma pesquisadora.
De acordo com Caldeira et al. (2007), a avaliação regular do escore de condição corporal é a ferramenta mais prática de monitoramento dos mecanismos de controle das reservas corpóreas e, consequentemente, do status nutricional dos animais.

Verificou-se que as ovelhas recebendo ração com 2,0 Mcal EM/kg MS foram as únicas a apresentarem 
perda de peso e de condição corporal durante a gestação (Tabela 3). Segundo Charismiadou, Bizelis e Rogdakis (2000), a restrição alimentar durante a prenhez causa consideráveis mudanças no metabolismo das ovelhas. O fornecimento de um nível nutricional impróprio durante o terço final de gestação levaria os animais a utilizarem suas reservas corporais numa tentativa de manter o aporte de nutrientes adequados ao crescimento fetal, resultando em perda de peso das fêmeas.

A redução no peso e no escore de condição corporal durante a gestação nas ovelhas alimentadas com ração com 2,0 Mcal EM/kg MS indicou que este teor não atende a demanda nutricional dos animais desta categoria, já que houve a necessidade de mobilização de reservas corporais para desenvolvimento fetal.

De acordo com Sainz (2010), quando se busca a redução no intervalo de parto, não é conveniente que as reservas da mãe sejam direcionadas para o crescimento fetal, pois dessa forma, fica comprometido o êxito dos objetivos reprodutivos.

Da mesma forma, as ovelhas recebendo ração com 2,0 Mcal EM/kg MS apresentaram maior $(\mathrm{P}<0,05)$ variação negativa nesses parâmetros durante todo período experimental (Tabela 3) em decorrência da restrição energética, comprovando a limitação no desempenho dos animais recebendo a referida dieta. O teor de 2,4 Mcal EM/kg MS possibilitou variações de peso e de condição corporal positivas e superiores aos outros teores avaliados, tanto na gestação quanto no período total do experimento (Tabela 3 ).

Os animais alimentados com ração contendo 2,2 Mcal EM/kg MS praticamente não apresentaram variação na condição corporal durante o terço final da gestação (Tabela 3), indicando que este teor atende a exigência energética de ovelhas Santa Inês nesta fase.

Apesar de todos os teores de energia terem determinado perda de peso e escore (Tabela 3 ) no período inicial de lactação (do parto ao dia 28), provavelmente em função do desbalanço entre exigência energética e capacidade de ingestão, somente nos animais que receberam 2,4 Mcal EM/kg MS pode-se observar ganhos nessas características a partir do dia 28 de lactação. Isto sugere redução da exigência energética depois da quarta semana após o parto, ocasionada provavelmente pela diminuição na produção de leite, estando o teor energético de 2,4 Mcal EM/kg MS acima da demanda exigida para esta fase.

Susin (1996) propôs como ideal ao desmame o escore de condição corporal no valor de 2,5. As ovelhas que receberam 2,4 Mcal EM/kg de MS apresentaram média de escore de 3,24 por ocasião do desmame, valor bastante superior ao proposto. Desta forma, pelos resultados observados pode-se supor que, durante a lactação, houve desperdício na utilização de nutrientes pelas ovelhas do citado teor energético, pois estas possuíam reservas corporais suficientes para a produção de leite. Portanto, fazse desnecessária a manutenção das matrizes com elevada condição corporal nesta fase produtiva, fato que conduziria o produtor a perdas econômicas.

Notou-se também que no período final de lactação, após a quarta semana do parto, a variação no escore das ovelhas alimentadas com ração contendo 2,2 Mcal EM/kg de MS mostrou-se ligeiramente negativa $(-0,09)$ e, de acordo com a equação de regressão proposta $(\hat{\mathrm{Y}}=4,69 \mathrm{x}-7,91)$, o teor energético de 2,23 Mcal EM/kg MS nesta fase proporcionaria variação zero na condição corporal das matrizes. Os animais que receberam esta ração apresentaram média de escore de 2,44 ao final da lactação. Caso não houvesse variação no escore das ovelhas deste grupo após os 28 dias de lactação, as mesmas atingiriam a desmama com média de ECC muito próxima a 2,5, valor considerado ideal por Susin (1996) para esta fase. Já os animais recebendo ração com 2,0 Mcal EM/kg MS apresentaram escore de 1,53 ao final da lactação, valor muito inferior ao considerado ideal. 
As mesmas tendências seguidas por pesos e escores corporais observadas neste trabalho são devidas as significativas $(\mathrm{P}<0,05)$ correlações positivas $(\mathrm{r}=0,56 ; 0,62 ; 0,62 ; 0,66 ; 0,73$ para o parto, 7, 14, 28 dias pós-parto e desmama, respectivamente) entre estas duas características, também relatadas por Castro et al. (2012).

Também foi verificado efeito linear dos teores de energia no peso ao nascimento dos cordeiros (Tabela 4), sendo os filhos de ovelhas alimentadas com ração contendo 2,4 Mcal EM/kg MS aqueles que apresentaram as maiores médias $(\mathrm{P}<0,05)$.

A menor média de peso ao nascer registrada para cordeiros filhos de ovelhas que receberam ração com 2,0 Mcal EM/kg MS (3,77 kg) demonstrou o comprometimento do crescimento fetal em decorrência de uma alimentação deficiente energeticamente oferecida à fêmea gestante. Estes resultados confirmam relatos de Dwyer (2003) de que ovelhas que necessitam mobilizar reservas corporais durante a gestação produzem cordeiros mais leves.

Geraseev et al. (2006) também relataram efeito da restrição nutricional no terço final da gestação de ovelhas sobre o crescimento de fetos ovinos. Cordeiros com restrição alimentar antes do nascimento apresentaram média de peso ao nascer de $3,02 \mathrm{~kg}$.

Os valores médios para peso ao nascimento de 4,44 kg e 4,19 kg (para os teores 2,4 e 2,2 Mcal EM/ $\mathrm{kg}$ MS, respectivamente) são superiores ao valor de $3,96 \mathrm{~kg}$ observado por Ribeiro et al. (2008a), em cordeiros da raça Santa Inês provenientes de partos simples. Já Mexia et al. (2004) informaram peso médio ao nascimento de $3,36 \mathrm{~kg}$, para cordeiros da mesma raça.

Não houve nenhum registro de distocia, demonstrando que mesmo o teor energético mais elevado não causou crescimento fetal excessivo.

A relevância da avaliação do peso ao nascimento consiste no fato desta variável estar positivamente correlacionada com a velocidade de crescimento $(\mathrm{r}=0,47 ; \mathrm{P}<0,01)$, representada pelo ganho de peso, e com a taxa de sobrevivência pós-natal dos cordeiros, como comprovado por Castro et al. (2012). Portanto, é uma variável indicativa da eficiência produtiva do rebanho. Houve efeito linear crescente $(\mathrm{P}<0,05)$ dos teores de energia em todas as outras pesagens dos cordeiros e no ganho médio diário de peso (Tabela 4).

O peso do cordeiro ao desmame sofre influência direta da produção de leite da mãe (MOHAMMADI et al., 2010) que, por sua vez, é afetada pelo teor energético da alimentação da matriz (CASTRO et al., 2012).

Cordeiros provenientes de ovelhas que receberam rações contendo 2,0 e 2,2 Mcal EM/kg MS foram respectivamente desmamados com 6,12 e 3,0 kg, em média, a menos que aqueles do teor 2,4 Mcal EM/kg MS.

No desmame realizado aos 60 dias, os pesos apresentados pelos animais filhos de ovelhas recebendo rações com 2,2 e 2,4 Mcal EM/kg MS $(14,69$ e 17,69 kg, respectivamente) foram superiores aos 13,02 kg relatados por Mexia et al. (2004) para cordeiros provenientes de partos simples. 
Tabelas 4. Médias de peso (kg) das crias do nascimento ao desmame e ganho médio diário de peso (GMDP) para os diferentes teores energéticos.

\begin{tabular}{|c|c|c|c|c|c|c|}
\hline \multirow[b]{2}{*}{ Variável } & \multicolumn{3}{|c|}{ Teor de energia metabolizável(Mcal / kg de MS) } & \multirow[b]{2}{*}{ Regressão $^{1}$} & \multirow[b]{2}{*}{$\mathrm{R}^{2}$} & \multirow[b]{2}{*}{$\mathrm{CV}(\%)$} \\
\hline & $2,0(n=18)$ & $2,2(n=19)$ & $2,4(n=18)$ & & & \\
\hline Nascimento & 3,77 & 4,19 & 4,44 & $\hat{y}=1,50 x+0,92$ & 0,98 & 16,58 \\
\hline Dia 7 & 4,91 & 5,49 & 6,04 & $\hat{y}=2,62 x-0,20$ & 0,99 & 16,20 \\
\hline Dia 28 & 8,02 & 9,48 & 10,94 & $\hat{y}=7,19 x-6,20$ & 0,99 & 17,74 \\
\hline Desmame (60 dias) & 11,57 & 14,69 & 17,69 & $\hat{y}=15,32 x-19,01$ & 0,99 & 20,31 \\
\hline GMDP & 0,125 & 0,176 & 0,220 & $\hat{y}=0,230 x-0,332$ & 0,99 & 25,71 \\
\hline
\end{tabular}

$\mathrm{n}=$ número de animais; $\mathrm{R}^{2}=$ coeficiente de determinação; $\mathrm{CV}=$ coeficiente de variação

${ }^{1}$ Regressão linear significativa $(\mathrm{P}<0,05)$

Fonte: Elaboração dos autores.

O ganho de peso dos cordeiros pode ser destacado como importante parâmetro do desempenho produtivo (MEXIA et al., 2004). Esses pesquisadores, assim como Castro et al. (2012), afirmaram que a velocidade de crescimento da cria está sob influência da nutrição materna, informação comprovada pelos resultados deste experimento.

Crias de ovelhas que foram alimentadas com rações contendo 2,0 e 2,2 Mcal EM/kg MS obtiveram, respectivamente, ganhos médios diário em peso $43 \%$ e $20 \%$ inferiores aos cordeiros oriundos de fêmeas que receberam ração com 2,4 Mcal EM/kg MS.

O ganho de peso dos cordeiros apresentou correlação positiva com o peso $(\mathrm{r}=0,69 ; \mathrm{P}<0,01)$ e com o escore da mãe ao parto $(\mathrm{r}=0,54 ; \mathrm{P}<0,01)$, mostrando que as crias de ovelhas mais pesadas e com melhor condição corporal ao parto crescem mais rapidamente até o desmame.

A subnutrição pré-natal não está necessariamente associada ao baixo peso ao nascimento (RAE et al., 2001) nem tem obrigatoriamente consequências negativas nas primeiras semanas de vida, sendo que alguns efeitos podem ser evidenciados em estágios mais avançados na vida do animal (MARTIN;
RODGER; BLACHE, 2004). Tais prejuízos estão relacionados com a diferenciação e desenvolvimento do sistema reprodutivo (RAE et al., 2001) e com a formação das fibras musculares (GREENWOOD et al., 2000), características determinantes da eficiência reprodutiva e da qualidade da carcaça, respectivamente.

A eficiência de produção ( $\mathrm{kg}$ de cordeiros desmamados por $\mathrm{kg}$ de ovelhas) mostrou-se diferente $(\mathrm{P}<0,01)$ entre as dietas oferecidas, apresentando médias de 0,207; 0,280 e 0,341, para os teores 2,0; 2,2 e 2,4 Mcal EM/kg MS, respectivamente.

O sexo da cria e a época de realização do experimento não influenciaram $(\mathrm{P}>0,05)$ os pesos e os escores de condição corporal das ovelhas (Tabela 5).

Pacheco e Quirino (2008) afirmaram que o ano de observação influencia no peso dos animais principalmente em função das diferenças na quantidade e qualidade de forragem disponível. O fato dos animais terem sido mantidos confinados durante o final da gestação e lactação com a utilização de silagem como fonte de volumoso pode explicar, em parte, a ausência de diferenças nos pesos e nos escores de condição corporal das ovelhas entre as épocas avaliadas. 
Tabela 5. Médias de peso (kg) e escores de condição corporal (escala de 1 a 5) das ovelhas antes e após o parto para sexo da cria e época de observação.

\begin{tabular}{|c|c|c|c|c|c|c|c|c|}
\hline \multirow[b]{2}{*}{ Variável } & \multicolumn{2}{|c|}{ Sexo da cria } & \multirow[b]{2}{*}{$\operatorname{Pr}>\mathrm{F}$} & \multicolumn{3}{|c|}{ Época $^{1}$} & \multirow[b]{2}{*}{$\operatorname{Pr}>\mathrm{F}$} & \multirow[b]{2}{*}{$\mathrm{CV}(\%)$} \\
\hline & $\begin{array}{l}\text { Macho } \\
(\mathrm{n}=32)\end{array}$ & $\begin{array}{l}\text { Fêmea } \\
(\mathrm{n}=23)\end{array}$ & & $I(n=16)$ & II $(n=19)$ & III $(n=20)$ & & \\
\hline \multicolumn{9}{|c|}{ Pesos } \\
\hline Inicial & 51,70 & 53,68 & 0,3912 & 55,14 & 53,42 & 49,52 & 0,1148 & 14,42 \\
\hline Parto & 54,22 & 55,44 & 0,6261 & 55,90 & 52,78 & 55,81 & 0,4879 & 15,08 \\
\hline Dia 7 & 53,69 & 55,90 & 0,3845 & 54,70 & 53,19 & 56,46 & 0,5446 & 15,40 \\
\hline Dia 28 & 52,19 & 55,33 & 0,2043 & 53,14 & 52,66 & 55,48 & 0,5707 & 15,07 \\
\hline Desmame (60 dias) & 50,67 & 54,72 & 0,1133 & 51,54 & 52,66 & 53,88 & 0,7340 & 15,69 \\
\hline \multicolumn{9}{|c|}{ Escore de Condição Corporal } \\
\hline Inicial & 3,15 & 2,88 & 0,1413 & 3,13 & 2,99 & 2,93 & 0,6220 & 19,76 \\
\hline Parto & 3,00 & 2,94 & 0,6860 & 2,74 & 3,07 & 3,10 & 0,1216 & 17,29 \\
\hline Dia 7 & 2,79 & 2,73 & 0,7039 & 2,54 & 2,82 & 2,91 & 0,1249 & 18,60 \\
\hline Dia 28 & 2,56 & 2,49 & 0,6622 & 2,42 & 2,50 & 2,66 & 0,4143 & 20,18 \\
\hline Desmame (60 dias) & 2,35 & 2,45 & 0,5426 & 2,28 & 2,28 & 2,64 & 0,1152 & 22,63 \\
\hline
\end{tabular}

$\mathrm{n}=$ número de observações; $\mathrm{CV}=$ coeficiente de variação; $\operatorname{Pr}>\mathrm{F}=$ probabilidade de significância

${ }^{1}$ Época I = fornecimento das dietas: set-dez de 2009; estação de monta: fev-mar de 2010

${ }^{1}$ Época II = fornecimento das dietas: jun-set de 2010; estação de monta: nov-dez de 2010

${ }^{1}$ Época III = fornecimento das dietas: mar-jun de 2011; estação de monta: ago-set de 2011

Fonte: Elaboração dos autores.

Com relação ao sexo da cria, os machos apresentaram maiores pesos $(\mathrm{P}<0,05)$ do nascimento aos 28 dias (Tabela 6). Cordeiros machos foram 0,$46 ; 0,63$ e 1,02 kg mais pesados ao nascimento, aos 7 e aos 28 dias, respectivamente. Apesar de não ter sido identificada diferença nos pesos de machos e fêmeas aos 60 dias, os cordeiros machos foram desmamados $1,16 \mathrm{~kg}$ mais pesados.

Tabelas 6. Médias de peso $(\mathrm{kg})$ das crias do nascimento ao desmame e ganho médio diário de peso (GMDP) para sexo da cria e época de observação.

\begin{tabular}{lcccccccc}
\hline & \multicolumn{3}{c}{ Sexo da cria } & & \multicolumn{3}{c}{ Época $^{1}$} & \\
\cline { 2 - 3 } Variável & $\begin{array}{c}\text { Macho } \\
(\mathrm{n}=32)\end{array}$ & $\begin{array}{c}\text { Fêmea } \\
(\mathrm{n}=23)\end{array}$ & $\operatorname{Pr}>\mathrm{F}$ & $\mathrm{I}(\mathrm{n}=16)$ & $\mathrm{II}(\mathrm{n}=19)$ & $\mathrm{III}(\mathrm{n}=20)$ & $\operatorname{Pr}>\mathrm{F}$ & $\mathrm{CV}(\%)$ \\
\hline Nascimento & $4,36 \mathrm{a}$ & $3,90 \mathrm{~b}$ & 0,0343 & 4,30 & 4,14 & 3,95 & 0,3904 & 16,90 \\
Dia 7 & $5,79 \mathrm{a}$ & $5,16 \mathrm{~b}$ & 0,0202 & 5,80 & 5,38 & 5,25 & 0,2031 & 15,77 \\
Dia 28 & $9,99 \mathrm{a}$ & $8,97 \mathrm{~b}$ & 0,0466 & 10,00 & 9,15 & 9,29 & 0,3361 & 17,26 \\
Desmame (60 dias) & 15,23 & 14,07 & 0,1955 & 15,57 & 14,10 & 14,28 & 0,3415 & 19,88 \\
GMDP & 0,181 & 0,167 & 0,2973 & 0,189 & 0,162 & 0,172 & 0,2634 & 25,96 \\
\hline
\end{tabular}

$\mathrm{n}=$ número de observações; $\mathrm{CV}=$ coeficiente de variação; $\operatorname{Pr}>\mathrm{F}=$ probabilidade de significância

${ }^{1}$ Época I = fornecimento das dietas: set-dez de 2009; estação de monta: fev-mar de 2010

${ }^{1}$ Época II = fornecimento das dietas: jun-set de 2010; estação de monta: nov-dez de 2010

${ }^{1}$ Época III = fornecimento das dietas: mar-jun de 2011; estação de monta: ago-set de 2011

Fonte: Elaboração dos autores.

A superioridade de peso em cordeiros machos pode ser observada em diversos trabalhos com animais de diferentes grupos genéticos (BARROS, VASCONCELOS; LOBO, 2004; MOHAMMADI 
et al., 2010; KORITIAKI et al., 2012). Diferenças nos cromossomos sexuais, provavelmente na posição dos genes relacionados ao crescimento, características fisiológicas e diferenças no sistema endócrino, especialmente nos hormônios sexuais, acarretam nas diferenças de crescimento entre animais de sexos distintos (PACHECO; QUIRINO, 2008; MOHAMMADI et al., 2010).

As médias de peso ao nascimento de machos $(4,36 \mathrm{~kg})$ e fêmeas $(3,90 \mathrm{~kg})$ são semelhantes às relatadas por Ribeiro et al. (2008a) para cordeiros da raça Santa Inês nascidos de partos simples e superiores às informadas por Mexia et al. (2004), que também encontraram médias inferiores à desmama, quando comparadas com as médias do presente trabalho.

Não foi observada diferença $(\mathrm{P}>0,05)$ no ganho médio diário de peso entre os sexos, resultado também encontrado por Koritiaki et al. (2012).

A produtividade ( $\mathrm{kg}$ de cordeiros desmamados por $\mathrm{kg}$ de ovelhas) foi influenciada $(\mathrm{P}<0,05)$ pelo sexo da cria, tendo sido os cordeiros machos avaliados como mais eficientes $(0,297$ e 0,255 , para machos e fêmeas, respectivamente).

Não houve diferença $(\mathrm{P}>0,05)$ entre os pesos e ganhos de peso de cordeiros nascidos em diferentes épocas ou anos, assim como reportado por Ribeiro et al. (2008b). Koritiaki et al. (2012) relataram diferenças nos pesos ao nascimento e ao desmame e no ganho médio de peso de cordeiros nascidos em diferentes anos.

Mohammadi et al. (2010) afirmaram que diferenças no crescimento de cordeiros observadas entre vários anos podem ocorrer em função de fatores climáticos, como precipitação, temperatura e umidade, que acarretam em variações tanto nos animais quanto na quantidade e na qualidade do alimento disponibilizado. Além desses fatores, mudanças no manejo e alterações na composição genética do rebanho podem contribuir para diferenças nos pesos dos cordeiros em diferentes anos.

A eficiência produtiva $(\mathrm{kg}$ de cordeiros desmamados por $\mathrm{kg}$ de ovelhas) foi semelhante $(\mathrm{P}>0,05)$ nas diferentes épocas de avaliação, sendo registrada média de 0,276.

O teor energético oferecido às ovelhas ao final da gestação e durante a lactação interferiu no desempenho reprodutivo subsequente (Tabela 7). Apesar da taxa de prenhez ter sido semelhante $(\mathrm{P}>0,05)$, com média de $92,6 \%$, as ovelhas sob diferentes dietas apresentaram diferenças $(\mathrm{P}<0,05)$ nas taxas de parição e nascimentos (Tabela 7). 
Tabelas 7. Índices reprodutivos e períodos de serviço apresentados pelas ovelhas de acordo com a dieta recebida no final da gestação e lactação, com o sexo da cria e com a época de realização.

\begin{tabular}{lcccc}
\hline & $\begin{array}{c}\text { Taxa de prenhez } \\
(\%)\end{array}$ & $\begin{array}{c}\text { Taxa de parição } \\
(\%)\end{array}$ & $\begin{array}{c}\text { Taxa de } \\
\text { nascimento (\%) }\end{array}$ & $\begin{array}{c}\text { Período de } \\
\text { serviço } \text { (dias) }^{\circ}\end{array}$ \\
\hline Teor de energia metabolizável & & & & \\
2,0 Mcal / kg de MS (n=18) & 83,3 & $66,7 \mathrm{~b}$ & $72,2 \mathrm{~b}$ & 131,1 \\
2,2 Mcal / kg de MS (n=19) & 100,0 & $100,0 \mathrm{a}$ & $105,3 \mathrm{a}$ & 128,4 \\
2,4 Mcal / kg de MS (n=18) & 94,4 & $83,3 \mathrm{~b} \mathrm{ab}$ & $88,9 \mathrm{ab}$ & 122,2 \\
Pr>F & 0,1154 & 0,0148 & 0,0449 & 0,0302 \\
CV (\%) & 27,76 & 42,27 & 50,04 & 8,31 \\
\hline Sexo da cria & & & & \\
Macho (n=32) & 90,6 & $75,0 \mathrm{~b}$ & $78,1 \mathrm{~b}$ & $124,7 \mathrm{a}$ \\
Fêmea (n=23) & 95,7 & $95,7 \mathrm{a}$ & $104,3 \mathrm{a}$ & $130,9 \mathrm{~b}$ \\
Pr>F & 0,4788 & 0,0411 & 0,0364 & 0,0445 \\
\hline Época & & & & \\
I $(\mathrm{n}=16)$ & 100,0 & 81,3 & 81,3 & 124,2 \\
II (n=19) & 89,5 & 84,2 & 105,3 & 129,2 \\
III (n=20) & 90,0 & 85,0 & 80,0 & 130,0 \\
Pr>F & 0,5365 & 0,9520 & 0,9977 & 0,2302 \\
\hline
\end{tabular}

$\mathrm{n}=$ número de observações; $\mathrm{CV}=$ coeficiente de variação; $\mathrm{Pr}>\mathrm{F}=$ probabilidade de significância

$\mathrm{a}, \mathrm{b}=$ médias seguidas de letras diferentes na coluna, para o mesmo efeito, diferem $(\mathrm{P}<0,05)$ entre si

${ }^{1}$ Período de serviço $=-21,08 \mathrm{x}+173,50(\mathrm{P}<0,05)$; onde $\mathrm{x}$ representa o teor energético da dieta; $\mathrm{R}^{2}=0,90$

${ }^{2}$ Época I = fornecimento das dietas: set-dez de 2009; estação de monta: fev-mar de 2010

${ }^{2}$ Época II = fornecimento das dietas: jun-set de 2010; estação de monta: nov-dez de 2010

${ }^{2}$ Época III = fornecimento das dietas: mar-jun de 2011; estação de monta: ago-set de 2011

Fonte: Elaboração dos autores.

Ovelhas recebendo rações com teores de 2,2 e 2,4 Mcal EM/kg de MS apresentaram desempenhos semelhantes nestes parâmetros reprodutivos avaliados nas estações de monta seguintes ao fornecimento das rações experimentais (Tabela 7). Já as fêmeas alimentadas com 2,0 Mcal EM/kg MS obtiveram os piores índices. Estes resultados podem ser explicados, em parte, pelos baixos pesos e escores de condição corporal apresentados durante a estação de monta, pelas ovelhas alimentadas com menor teor energético na ração (Tabela 8). Esta afirmação pode ser sustentada pelos resultados encontrados por Gonzalez, Labuonora e Russel (1997) que relataram piores desempenhos reprodutivos pelas fêmeas mais leves e mais magras.

Tabela 8. Médias de peso $(\mathrm{kg})$ e escores de condição corporal (escala de 1 a 5) das ovelhas ao início e ao final da estação de monta (EM) de acordo com a dieta recebida no final da gestação e lactação.

\begin{tabular}{|c|c|c|c|c|c|c|}
\hline \multirow[b]{2}{*}{ Variável } & \multicolumn{3}{|c|}{ Teor de energia metabolizável(Mcal / kg de MS) } & \multirow[b]{2}{*}{ Regressão } & \multirow[b]{2}{*}{$\mathrm{R}^{2}$} & \multirow[b]{2}{*}{$\mathrm{CV}(\%)$} \\
\hline & $2,0(n=18)$ & $2,2(n=19)$ & $2,4(n=18)$ & & & \\
\hline \multicolumn{7}{|c|}{ Pesos } \\
\hline 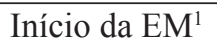 & 44,6 & 46,9 & 51,4 & $\hat{y}=13,17 x+18,59$ & 0,96 & 14,77 \\
\hline Final da EM & 47,1 & 48,8 & 52,4 & $\hat{y}=49,4$ & - & 15,55 \\
\hline \multicolumn{7}{|c|}{ Escore de Condição Corporal } \\
\hline Início da $\mathrm{EM}^{1}$ & 2,06 & 2,51 & 3,17 & $\hat{y}=2,61 x-3,16$ & 0,99 & 21,63 \\
\hline Final da $\mathrm{EM}^{1}$ & 2,39 & 2,71 & 3,00 & $\hat{y}=1,06 x+0,40$ & 0,99 & 22,06 \\
\hline
\end{tabular}

$\mathrm{n}=$ número de animais; $\mathrm{R}^{2}=$ coeficiente de determinação; $\mathrm{CV}=$ coeficiente de variação

${ }^{1}$ Regressão linear significativa $(\mathrm{P}<0,05)$.

Fonte: Elaboração dos autores. 
Boucinhas, Siqueira e Maestá (2006), estudando efeito da suplementação de ovelhas em sistema de intervalo de parto de 8 meses, observaram que fêmeas não suplementadas ao final da gestação e durante a lactação apresentaram maiores perdas de reservas corporais após o parto, tendo comprometido o seu desempenho reprodutivo subsequente.

Para Robinson, Rooke e McEvoy (2002) o ECC ideal para o máximo desempenho reprodutivo dos animais encontra-se entre 3,0 e 3,5 em que pontuações muito acima ou abaixo deste intervalo determinam redução nos índices de fertilidade e prolificidade. Já Cezar e Sousa (2006) consideraram escores entre 3,0 e 4,0 como ideais para estação de monta.

Apesar das ovelhas que receberam ração com 2,2 Mcal EM/kg de MS terem apresentado média de escore corporal de 2,51 no início da estação de monta seguinte ao fornecimento das rações experimentais (Tabela 8), os resultados deste trabalho demonstram que esta condição não comprometeu os seus desempenhos reprodutivos (Tabela 7). Da mesma forma, Ribeiro et al. (2003) sugeriram o escore de 2,5 como o mínimo para se ter taxas reprodutivas aceitáveis.

Ovelhas alimentadas com ração contendo 2,0 Mcal EM/kg de MS desmamaram a cria com média de escore corporal de 1,53 (Tabela 3 ) e chegaram à estação de monta seguinte com média de 2,06 (Tabela 8). Portanto, com o manejo utilizado do desmame a reprodução, não houve espaço de tempo suficiente para que as matrizes que receberam o teor energético mais baixo recuperassem sua condição corporal para expressarem taxas reprodutivas satisfatórias, já que, de acordo com Ribeiro et al. (2003), a taxa de parição de $66,7 \%$ (Tabela 7) pode ser considerada crítica em sistemas de produção de cordeiros.

Como consequência do inadequado aporte nutricional oferecido pela dieta com 2,0 Mcal EM/ $\mathrm{kg}$ de MS durante o final da gestação e lactação, houve aumento na duração do anestro pós-parto, evidenciado pelo alongamento no período de serviço (Tabela 7) que apresentou resposta linear negativa $(\mathrm{P}<0,05)$ em função do teor energético adotado. Como resultado do prolongamento do período de serviço e, consequentemente do intervalo de parto, pode-se ter um menor número de crias desmamadas por matriz a cada ano, levando a uma redução na eficiência produtiva.

Sainz (2010) afirmou que para a redução do intervalo de parto é imprescindível o correto manejo nutricional não só no período que antecede a cobertura, mas também durante a gestação e lactação. Os resultados obtidos neste experimento demonstram existir elevada correlação positiva entre o ECC ao parto e ao desmame com a sua mensuração no início da estação de monta subsequente $(\mathrm{r}=0,64$; $\mathrm{r}=0,82 ; \mathrm{P}<0,01)$.

Segundo Cezar e Sousa (2006), a baixa herdabilidade da maioria dos parâmetros reprodutivos torna imprescindível a melhoria de todas as medidas de natureza ambiental causadoras de impactos positivos na taxa reprodutiva do rebanho. Com os resultados obtidos neste trabalho, pode-se afirmar que o adequado manejo nutricional de matrizes é uma estratégia eficiente para alcançar tais objetivos.

O sexo do cordeiro criado pela ovelha não influenciou $(\mathrm{P}<0,05)$ a taxa de prenhez ao final da subsequente estação de monta. Entretanto, o sexo da cria afetou as taxas de parição e de nascimento, sendo que ovelhas que criaram fêmeas apresentaram, posteriormente, as melhores médias para estes parâmetros, superiores em 20,7 e 26,2 pontos percentuais, respectivamente (Tabela 7). Estes resultados demonstram que as ovelhas que criaram machos estiveram sujeitas, na gestação seguinte, a perdas embrionária e/ou fetais.

O período de serviço também foi influenciado $(\mathrm{P}<0,05)$ pelo sexo da cria (Tabela 7$)$. Ovelhas que pariram e criaram machos conceberam, em média, com seis dias de antecedência, fato que não contribuiu para melhorar outros índices reprodutivos 
destes animais, como relatado anteriormente.

A época de realização do experimento não influenciou $(\mathrm{P}>0,05)$ nenhum dos parâmetros reprodutivos avaliados (Tabela 7), demonstrando semelhante atividade reprodutiva da raça Santa Inês para as diferentes épocas do ano contempladas neste trabalho. Já Ribeiro et al. (2008b), trabalhando com animais Corriedale, Hampshire Down, Ile de France e Suffolk, relataram diferenças nas taxas de parição das matrizes acasaladas em diferentes épocas do ano.

\section{Conclusões}

Ovelhas Santa Inês podem ser utilizadas para produção de cordeiros em sistema de acasalamento acelerado, desde que seja controlado o manejo nutricional do rebanho visando a manutenção de escores corporais intermediários (2,5 a 3,5). Dieta contendo 2,0 Mcal EM/kg de MS não atende as exigências de ovelhas Santa Inês em final de gestação e durante a lactação.

\section{Referências}

BARROS, N. N.; VASCONCELOS, V. R.; LOBO, R. N. B. Características de crescimento de cordeiros F1 para abate no semi-árido do Nordeste do Brasil. Pesquisa Agropecuária Brasileira, Brasília, v. 39, n. 8, p. 809-814, 2004.

BOUCINHAS, C. C.; SIQUEIRA, E. R.; MAESTÁ, S. A. Dinâmica do peso e da condição corporal e eficiência reprodutiva de ovelhas da raça Santa Inês e mestiças Santa Inês-Suffolk submetidas a dois sistemas de alimentação em intervalos entre partos de oito meses. Ciência Rural, Santa Maria, v. 36, n. 3, p. 904-909, 2006.

BROLIO, M. P.; AMBRÓSIO, C. E.; FRANCIOLLI, A. R.; MORINI, A. C.; GUERRA, R. R.; MIGLINO, M. A. A barreira placentária e sua função de transferência nutricional. Revista Brasileira de Reprodução Animal, Belo Horizonte, v. 34, n. 4, p. 222-232, 2010.

CALDEIRA, R. M.; BELO, A. T.; SANTOS, C. C.; VAZQUES, M. I.; PORTUGAL, A. V. The effect of long-term feed restriction and over-nutrition on body condition score, blood metabolites and hormonal profiles in ewes. Small Ruminant Research, Amsterdam, v. 68, n. 3, p. 242-255, 2007.

CASTRO, F. A. B.; RIBEIRO, E. L. A.; MIZUBUTI, I. Y.; SILVA, L. D. F.; BARBOSA, M. A. A. F.; SOUSA, C. L.; PAIVA, F. H. P.; KORITIAKI, N. A. Influence of pre and postnatal energy restriction on the productive performance of ewes and lambs. Revista Brasileira de Zootecnia, Viçosa, v. 41, n. 4, p. 951-958, 2012.

CAVIGLIONE, J. H.; KIIHL, L. R. B.; CARAMORI, P. H.; OLIVEIRA, D. Cartas climáticas do Paraná. 2000. Disponível em: <http://www.iapar.br/modules/conteudo/ conteudo.php?conteudo=677>. Acesso em: 19 nov. 2012.

CEZAR, M. F.; SOUSA, W. H. Avaliação e utilização da condição corporal como ferramenta de melhoria da reprodução e produção de ovinos e caprinos de corte. In: REUNIÃO ANUAL DA SOCIEDADE BRASILEIRA DE ZOOTECNIA, 43., 2006, João Pessoa. Anais... João pessoa: SBZ, 2006. p. 541-565.

CHARISMIADOU, M. A.; BIZELIS, J. A.; ROGDAKIS, E. Metabolic changes during the perinatal period in dairy sheep in relation to level of nutrition and breed: I. Late pregnancy. Journal of Animal Physiology and Animal Nutrition, Malden, v. 84, n. 3-4, p. 61-72, 2000.

CUNNINGHAM, J. G.; KLEIN, B. G. Tratado de fisiologia veterinária. 4. ed. Rio de Janeiro: Elsevier, 2008. $710 \mathrm{p}$.

DWYER, C. M. Behavioural development in the neonatal lamb: effect of maternal and birth-related factors. Theriogenology, Amsterdam, v. 59, n. 3-4, p. 1027-1050, 2003.

FRANDSON, R. D.; WILKE, W. L.; FAILS, A. D. Anatomia e fisiologia dos animais de fazenda. 6. ed. Rio de Janeiro: Guanabara Koogan, 2005. 454 p.

GERASEEV, L. C.; PEREZ, J. R. O.; CARVALHO, P. A.; OLIVEIRA, R. P.; QUINTÃO, F. A.; LIMA, A. L. Efeitos das restrições pré e pós-natal sobre o crescimento e o desempenho de cordeiros Santa Inês do nascimento ao desmame. Revista Brasileira de Zootecnia, Viçosa, v. 35, n. 1, p. 245-251, 2006.

GONZALEZ, R. E.; LABUONORA, D.; RUSSEL, J. F. The effects of ewe live weight and body condition score around mating on production from four sheep breeds in extensive grazing systems in Uruguay. Animal Science, Cambridge, v. 64, n. 1, p. 139-145, 1997.

GREENWOOD, P. L.; HUNT, A. S.; HERMANSON, J. W.; BELL, A. W. Effects of birth weight and postnatal nutrition on neonatal sheep: II. Skeletal muscle growth and development. Journal of Animal Science, Champaign, v. 78, n. 1, p. $50-61,2000$. 
HOFFMANN, R. P. Diagnóstico de parasitismo veterinário. Porto Alegre: Sulina, 1987. 156 p.

INSTITUTO BRASILEIRO DE GEOGRAFIA E ESTATÍSTICA - IBGE. Pesquisa pecuária municipal. 2013. Disponível em: <http://www.sidra.ibge.gov.br/ bda/tabela/listabl.asp? $\mathrm{c}=73 \& \mathrm{z}=\mathrm{t} \& \mathrm{o}=23>$. Acesso em: 18 set. 2013.

KORITIAKI, N. A.; RIBEIRO, E. L. A.; SCERBO, D. C.; MIZUBUTI, I. Y.; SILVA, L. D. F.; BARBOSA, M. A. A. F.; SOUZA, C. L.; PAIVA, F. H. P. Fatores que afetam o desempenho de cordeiros Santa Inês puros e cruzados do nascimento ao desmame. Revista Brasileira de Saúde e Produção Animal, Salvador, v. 13, n. 1, p. 258-270, 2012.

MARTIN, G. B.; RODGER, J.; BLACHE, D. Nutritional and environmental effects on reproduction in small ruminants. Reproduction, Fertility and Development, Collingwood, v. 16, n. 4, p. 491-501, 2004.

McDOWELL, L. R.; CONRAD, J. H.; THOMAS, J. E.; HARRIS, L. E. Latin american tables of feed composition. Gainesville: University of Florida, 1974. 509 p.

MELLOR, D. J. Nutritional effects on the fetus and mammary gland during pregnancy. Proceedings of the Nutrition Society, Cambridge, v. 46, n. 2, p. 249-257, 1987.

MEXIA, A. A.; MACEDO, F. A. F.; ALCALDE, C. R.; SAKAGUTI, E. S.; MARTINS, E. N.; ZUNDT, M.; YAMAMOTO, S. M.; MACEDO, R. M. G. Desempenho reprodutivo e produtivo de ovelhas Santa Inês suplementadas em diferentes fases da gestação. Revista Brasileira de Zootecnia, Viçosa, v. 33, n. 3, p. 658-667, 2004.

MIZUBUTI, I. Y.; PINTO, A. P.; PEREIRA, E. S.; RAMOS, B. M. O. Métodos laboratoriais de avaliação de alimentos para animais. Londrina: EDUEL, 2009. $228 \mathrm{p}$.

MOHAMMADI, K.; BEYGI NASSIRI, M. T.; FAYAZI, J.; ROSHANFEKR, H. Investigation of environmental factors influence on pre-weaning growth traits in Zandi lambs. Journal of Animal and Veterinary Advances, Pakistan, v. 9, n. 6, p. 1011-1014, 2010.

NATIONAL RESEARCH COUNCIL - NRC. Nutrient requirement of small ruminants: sheep, goats, cervids and new world camelids. Washington: National Academy Press, 2007. 384 p.

Nutrient requirements of sheep. $6^{\text {thed. }}$ Washington: National Academy Press. 1985. 112 p.

OSÓRIO, J. C. S.; OSÓRIO, M. T. M. Produção de carne ovina: técnicas de avaliação "in vivo" e na carcaça. 2. ed.
Pelotas: Ed. Universitária, UFPEL, 2005. 82 p.

PACHECO,A.; QUIRINO,C.R.Estudo das características de crescimento em ovinos. Pubvet, Londrina, v. 2, n. 29, Ed. 40, Art. 293, 2008. Disponível em: <http://www. pubvet.com.br/artigos_det.asp?artigo $=293>$. Acesso em: 18 jul. 2013.

PILAR, R. C.; PÉREZ, R. J. O.; SANTOS, C. L. Manejo reprodutivo da ovelha: recomendação para uma parição a cada oito meses. Boletim Agropecuário, Lavras, n. 50, p. 1-28, out. 2002.

RAE, M. T.; PALASSIO, S.; KYLE, C. E.; BROOKS, A. N.; LEA, R. G.; MILLER, D. W.; RHIND, S. M. Effect of maternal undernutrition during pregnancy on early ovarian development and subsequent follicular development in sheep fetuses. Reproduction, Bradley Stoke, v. 122, n. 6, p. 915-922, 2001.

RIBEIRO, A. C.; SANTANA, A. F.; LIMA, M. C.; SOUZA, R. S.; NASCIMENTO, J. P. V. Peso ao nascer de ovinos da raça Santa Inês no município de Irará - Bahia. Pubvet, Londrina, v. 2, n. 32, Ed. 43, Art. 294, 2008 a. Disponível em: $<$ http://www.pubvet.com.br/artigos_det. asp?artigo=294> . Acesso em: 18 jul. 2013.

RIBEIRO, E. L. A.; MIZUBUTI, I. Y.; SILVA, L. D. F.; ROCHA, M. A.; MORI, R. M. Desempenho produtivo de ovelhas submetidas a acasalamentos no verão e no outono no Norte do Paraná. Semina: Ciências Agrárias, Londrina, v. 29, n. 1, p. 229-236, 2008b.

RIBEIRO, L. A. O.; FONTANA, C. S.; WALD, V. B.; GREGORY, R. M.; MATTOS, R. C. Relação entre a condição corporal e a idade das ovelhas no encarneiramento com a prenhez. Ciência Rural, Santa Maria, v. 33, n. 2, p. 357-361, 2003.

ROBINSON, J. J.; ROOKE, J. A.; McEVOY, T. G. Nutrition for conception and pregnancy. In: FREER, M.; DOVE, H. (Ed.). Sheep nutrition. Wallingford: CAB International, 2002. p. 189-211.

SAINZ, J. M. G. Estrategias de la alimentación en el ganado ovino de carne. In: CONGRESSO INTERNACIONAL FEINCO, 5., 2010, São Paulo. Anais... São Paulo: Agrocentro, 2010. CD-ROM.

SINCLAIR, L. A.; WILKINSON, R. G. Feeding Systems for Sheep. In: THEODOROU, M. K.; FRANCE, J. Feeding Systems and feed evaluation models. Wallingford: CABI, 1999. p. 155-180.

SNIFFEN, C. J.; O'CONNOR, J. D.; VAN SOEST, P. J.; FOX, D. G.; RUSSELL, J.B. A net carbohydrate and protein system for evaluating cattle diets: II. Carbohydrate and protein availability. Journal of Animal Science, Champaign, v. 70, n. 11, p. 3562-3577, 1992. 
SUSIN, I. Exigências nutricionais de ovinos e estratégias de alimentação. In: SILVA SOBRINHO, A.G.; BATISTA, A. M. V.; SIQUEIRA, E. R. (Ed.). Nutrição de ovinos. Jaboticabal: Funep, 1996. p. 119-141.
VALADARES FILHO, S. C.; PINA, D. S. Fermentação ruminal. In: BERCHIELLI, T. T.; PIRES, A. V.; OLIVEIRA, S. G. Nutrição de ruminantes. 2. ed. Jaboticabal: FUNEP, 2011. p. 151-182. 